\title{
Looking fresh
}

\author{
Philip Machanick sacj.editor@gmail.com \\ Department of Computer Science, Rhodes University, Grahamstown, South Africa
}

\section{New Look}

SACJ has had a layout designed for print up to now. For print, if you are trying to save paper count and therefore use a small font, it becomes difficult for the eye to follow a long line. That is why multiple columns were invented. Now that the journal is published online, there is no strong reason to maintain a layout designed for print with a small font and two columns. Two columns make for difficult reading on a small screen as you have to read to the bottom of a left-side column then scroll back up for the next column. Two-column layout also makes it hard to fit in decent-sized figures and tables, leading to a compromise of allowing them to run across both columns if necessary. Going to single-column layout removes all these problems.

We have also decided to modify our referencing style to a widely-used standard, the American Psychological Association 6th edition style. This makes it easier for us to source a BibT $\mathrm{E}$ style, as well as for authors not using $\mathrm{ET}_{\mathrm{EX}}$ to format their work without worrying about quirks in referencing style unique to this journal. The APA 6th has a few quirks of its own. For example, if you cite 6 or more authors, the citation should always only name one author with "et al." for the rest. A citation of up to 2 authors should name all of them. Otherwise, you name all of them on first citation, then use "et al." subsequently. Fortunately, BibT $_{\mathrm{E}} \mathrm{X}$ takes care of all this and our production editor will handle that complication for you if you use Microsoft Word. You should aim to make your manuscript for review look reasonably close to the published style but do not worry about this level of detail.

We hope you will like the new look. I would like to thank production editor James Dibley for his hard work in rewriting the $\mathrm{HT}_{\mathrm{E}} \mathrm{X}$ class file. We will update the $\mathrm{BT}_{\mathrm{E}} \mathrm{X}$ and Microsoft Word instructions and files on the journal web site after review by the editorial team.

This issue also marks the end of our acceptance of the ACM 1998 classification scheme. From the next issue onwards, we will be using only the newer 2012 scheme. Another change in 2015: we will shift from a pure issue number scheme to volume (signifying the year) and issue number (numbered within volume), to be more in line with common referencing standards.

\section{In this issue}

Papers in this issue include a Viewpoint article and five research papers.

Machanick, P. (2015). Looking fresh [Editorial]. South African Computer Journal 57, vii-viii. DOI TBC

Copyright (C) the author(s); published under a Creative Commons NonCommercial 4.0 License (CC BY-NC 4.0).

SACJ is a publication of the South African Institute of Computer Scientists and Information Technologists Constitution.

ISSN 1015-7999 (print) ISSN 2313-7835 (online). 


\section{Research Articles}

Kotzé and Wolff in "Syllabification and parameter optimisation in Zulu to English machine translation" advance the art of statistical machine translation using Zulu to English translation as an example.

Mitchley proves an upper bound for discretisation performance of an aspect of reinforcement learning in "Upper Bounds on the Performance of Discretisation in Reinforcement Learning".

"Virtual Learning System Usage in Higher Education - A Study at Two South African Institutions" by Padayachee et al. provides a comprehensive study of how two very different universities use virtual learning systems focusing on patterns of use rather than pedagogy.

Sanders and Alexander, in "A history of computing doctorates in South Africa from 1978 to 2014", chronicle the development of Computer Science and Information Systems doctoral study in South Africa, including trends in student population and subjects of research.

In "Synchronous Gesture Manipulation for Collaboration and Coordination of Co-located Business Process Modelling", Scholtz et al. report on a Design Science Research evaluation of a collaborative business process modelling approach that uses gesture manipulation.

\section{Viewpoint}

A Viewpoint is somewhere between a full paper and a letter to the editor, containing a position or a basis for provoking debate. In this issue, I contribute such an article. To avoid any perception that I am using my own journal unfairly, this Viewpoint was reviewed more rigorously than usual - but it still does not count as a peer-reviewed paper. In "How General-Purpose can a GPU be?" I argue that GPUs could be redesigned to be much more tractable to general-purpose computation. 